\title{
Hot Water Extract of Triticum aestivum L. (Common Wheat) Ameliorates Renal Injury by Inhibiting Apoptosis in a Rat Model of Ischemia/Reperfusion
}

\author{
Hae Sook Baek ${ }^{1 \#}$, Sun Ha Lim, Ki Sung Ahn², Jong Won Lee ${ }^{1 *}$ \\ 1 : Department of Biochemistry, School of Medicine, Catholic University of Daegu, Daegu 705-718, Korea \\ 2 : Department of Internal Medicine, School of Medicine, Catholic University of Daegu, Daegu 705-718, Korea
}

\begin{abstract}
Objectives : Interruption and subsequent restoration of blood flow into the kidney result in renal injury. As an approach to preventing the renal injury, we determined the optimal conditions and the underlying mechanisms by which supernatant of hot water extract of ground Triticum aestivum L. (extract) attenuated ischemia/reperfusion (I/R) injury.

Methods : One hour after administration of the extract $(400 \mathrm{mg} / \mathrm{kg})$ by intraperitoneal injection, renal $\mathrm{I} / \mathrm{R}$ injury was generated by clamping the left renal artery in rats after surgical removal of the right kidney, followed by reperfusion. The maximal difference between the vehicle-treated and the extract-treated group under ketamine/xylazine or enflurane anesthetization was assessed at varying periods of ischemia (30-45 min) and reperfusion (3-48 hr), based on the renal function assessed with serum creatinine levels, tissue injury with hematoxylin/eosin staining, and apoptosis with terminal deoxynucleotidyltransferase-mediated dUTP nick-end labeling staining.

Results : Enflurane anesthetization with $40 \mathrm{~min}$ of ischemia and $24 \mathrm{hr}$ of reperfusion was identified to be the optimal condition, under which condition serum creatinine levels and tubular damage in the extract-treated group were significantly reduced compared with those in the vehicle-treated group (1.3 \pm 0.2 versus $2.7 \pm 0.3$ $\mathrm{mg} / \mathrm{dL}, P<0.01$, and average score $1.8 \pm 0.1$ versus $3.5 \pm 0.3, P<0.01$, respectively). These beneficial effects were mediated by inhibition of apoptotic cascades through attenuation of renal tissue malondialdehyde levels, $\mathrm{Bax} / \mathrm{Bcl}-2$ ratio and caspase -3 levels.

Conclusions : The extract conferred renal protection against ischemia/reperfusion injury in rats by scavenging reactive oxygen species and consequently blocking apoptotic cascades, plausibly augmented by enflurane protection.
\end{abstract}

Key words : Triticum aestivum L., water extract, kidney, ischemia/reperfusion, apoptosis Running Head: Triticum Effect on Renal Injury

\section{Introduction}

Ischemic acute renal failure, a subset of acute renal failure (ARF) (recently also referred to as acute kidney injury $)^{1)}$, is attributed to the reduction in blood flow to the kidney, leading to increase of creatinine concentration in the blood ${ }^{1,2)}$. In the severe cases of the event such as shock or cardiac surgery, interruption or prolonged reduction of blood flow results in ischemia to the kidney, especially in the outer medulla region, caused by combination of countercurrent oxygen exchange and selective reduction in blood supply ${ }^{3)}$, subsequently causing injury to the tubular cells due to depletion of $\mathrm{ATP}^{2,4)}$. Although early restoration of blood flow to the ischemic kidney is one way to prevent the ischemic $\mathrm{ARF}$, it further augments production of the reactive oxygen species (ROS), predisposing more injury to the

\footnotetext{
*Corresponding Author : Jongwon Lee, Department of Biochemistry, School of Medicine, Catholic University of Daegu, Daegu 705-718, Korea. · Tel : 82-53-650-4471 ·Fax : 82-53-621-9206 ·E-mail : leejw@cu.ac.kr

\#First Author : Hae Sook Baek, Department of Biochemistry, School of Medicine, Catholic University of Daegu, Daegu 705-718, Korea.

· Tel : 82-53-650-4499 · Fax : 82-53-621-9206 · E-mail : sftwtmt@hanmail.net

· 접수 : 2013년 4월 27일 ·수정 : 2013년 5월 6일 ·채택 : 2013년 5월 13일
} 
cells already weakened by ischemia,6). As a result of ischemia followed by reperfusion (ischemia/reperfusion, I/R), the tubular cells become dead by apoptosis as well as necrosis ${ }^{7)}$. Thus, one way to prevent ischemic $\mathrm{ARF}$ caused by I/R injury is to attenuate tubular cell death by eliminating ROS and consequently blocking apoptotic cascades mediated through reduction of Bax/Bcl-2 ratio, inhibition of procaspase-3 activation, and subsequent attenuation of generation of DNA nicks ${ }^{6,7)}$.

Triticum aestivum $\mathrm{L}$. has been consumed as a staple food for a long time. In addition, the light grains of Triticum aestivum L. has been prescribed for treating palpitations, insomnia and lack of concentration in traditional Chinese medicine ${ }^{8)}$. As another indication of Triticum aestivum L., we have reported that hot water extract of milled whole wheat (extract) ameliorated cultured neuronal cell death caused by $\beta$-amyloid added into the culture medium, resulting from reduced production of ROS mediated by up-regulation of glutathione, an essential endogenous antioxidant ${ }^{9)}$. Furthermore, administration of the extract alleviated hypoperfusion-induced chronic brain injury via inhibition of inflammatory reactions in rats subjected to bilateral ligation of carotid arteries ${ }^{10)}$. In the present study, we determined, in connection with our previous studies, whether the extract protected the kidney from I/R injury, accompanied by revealing the underlying mechanisms in relation to ablating ROS, using malondialdehyde as marker of lipid peroxidation ${ }^{11)}$, and also in relation to blocking the subsequent apoptotic cascades.

\section{Materials and Methods}

\section{Preparation of the extract}

The extract was prepared as described previously". Briefly, the grains of Triticum aestivum L., collected at Gurye, Jeonnam province, Korea, were ground in a mill, and ground Triticum aestivum L. was extracted in water at $90-100{ }^{\circ} \mathrm{C}$ for $1 \mathrm{hr}$. The whole extract was centrifuged to get supernatant, and the supernatant was concentrated with vacuum dryer, and then freeze-dried into powder. The extract was analyzed to be composed of $4.9 \%$ water, $5.9 \%$ ash, $7.9 \%$ protein, $0.2 \%$ fat, and $81.1 \%$ carbohydrate, including $15.4 \%$ total dietary fiber (TDF).

\section{Animals}

Eight-week-old male Sprague Dawley (SD) rats were purchased from Samtaco Inc. (Osan, Korea).
Experiments were carried out according to the guidelines for the animal care and use of laboratory animal protocols approved by the Institutional Animal Care and Research Advisory Committee of Catholic University of Daegu. Animals were housed with food and water available ad libitum under diurnal lighting conditions and in a temperature-controlled environment until the day of the experiment.

\section{Rat renal ischemia/reperfusion model}

Renal I/R injury was generated by clamping of the left renal artery in male SD rats (250-300 g) after surgical removal of the right kidney, as described previously, with some modifications ${ }^{12)}$. Rats were anesthetized either with intraperitoneal injections of ketamine $(100 \mathrm{mg} / \mathrm{kg})$ and xylazine $(5 \mathrm{mg} / \mathrm{kg})$ to identify the optimal period of ischemia, or first with $5 \%$ and then $3 \%$ inhalant enflurane for maintenance in $70 \%$ air and $30 \%$ oxygen to investigate whether enflurane provides protection. Unless stated otherwise, the following experimental conditions were used; the body temperature was maintained at $36 \pm 0.5{ }^{\circ} \mathrm{C}$ throughout the experiments (i. e. up to the end of anesthetization), with a heating pad (Harvard Apparatus, Holliston, MA). After midline incision, the right kidney was surgically removed. Then the remaining left kidney underwent renal artery occlusion by clamping for 40 min (ischemia), followed by recirculation of blood for another $24 \mathrm{hr}$ (reperfusion), after which the rats were sacrificed for further examinations. When rats were anesthetized with ketamine and xylazine, the following experimental conditions were selected: the body temperature, $36 \pm 0.5{ }^{\circ} \mathrm{C}$; periods of ischemia, 30, 35, 40 or $45 \mathrm{~min}$; period of reperfusion, $24 \mathrm{hr}$. When rats were anesthetized with enflurane, the following experimental conditions were selected: the body temperature, $36 \pm 0.5{ }^{\circ} \mathrm{C}$; period of ischemia, $40 \mathrm{~min}$; periods of reperfusion, $3,6,12,18,24$ or $48 \mathrm{hr}$.

\section{Extract administration}

Rats were randomly assigned to one of three groups: (1) extract-treated group (I/R + extract), (2) vehicle-treated group (I/R), or (3) sham group. In the extract-treated group, rats received the extract (400 $\mathrm{mg} / \mathrm{kg}$ ) dissolved in $0.9 \%$ saline by intraperitoneal injection $1 \mathrm{hr}$ prior to occlusion. In the vehicle-treated group, rats received $0.9 \%$ saline only by intraperitoneal injection $1 \mathrm{hr}$ prior to occlusion. In the sham group, experimental procedures were the same as those in the vehicle-treated group, except that there was no occlusion by clamping. 


\section{Serum creatinine levels}

At the end of increasing periods of reperfusion (3, $6,12,18,24$ or $48 \mathrm{hr}$ ), blood was collected from renal vein under anesthesia either with inhalant enflurane or with ketamine/xylazine, as described above. The serum creatinine concentration was measured by the Jaffè reaction on a Hitachi 747 analyzer (Roche Diagnostics, Germany).

\section{Malondialdehyde levels}

Malondialdehyde (MDA) generated from peroxidation of lipids in the renal tissue was measured using BIOXYTECH MDA-586 kits (OxisResearch, Portland, OR), as described previously ${ }^{13)}$. Briefly, the kidney tissue was weighed, 2.5-fold phosphate-buffered solution (PBS) (vol/wt) and butylated hydroxytoluene (5 mM) added, and then homogenized. After centrifugation at $10,000 \mathrm{~g}$ for $15 \mathrm{~min}, \mathrm{~N}$-methyl-2-phenylindole (NMPI) $(640 \mu \mathrm{L})$ and concentrated hydrochloric acid (150 $\mu \mathrm{L})$ were added successively to the supernatant (200 $\mu \mathrm{L})$. The reaction mixture was kept at $45{ }^{\circ} \mathrm{C}$ for $60 \mathrm{~min}$, and centrifuged again at $10,000 \mathrm{~g}$ for $15 \mathrm{~min}$. The color intensity of the supernatant was measured at 586 $\mathrm{nm}$. Concentrations of MDA in the sham, vehicle-treated and extract-treated groups were compared after the concentration of $\mathrm{MDA}$ in the sham group was set $100 \%$.

\section{Histological analysis}

After blood was collected, rats were sacrificed. Subsequently, the remaining left kidney was harvested, the sections prepared, and stained with hematoxylin and eosin, as described previously ${ }^{14)}$. Twenty representative photomicrographs were randomly taken in the outer medulla region of one representative section at $200 \mathrm{x}$ magnification under light microscope. Percentage of damaged area in the section was assessed by computer-aided image analysis (Image J), from which the degree of damage was graded by a 5-point scale (0-4) adopted by Kelly et al. ${ }^{15)}$, with a slight modification in assigning the range of scores: 0, none; 1, 〈5\%; 2, 5-30\%; 3, 30-50\%; 4, >50\%. Scores of the 20 sections were averaged to represent a score for each rat.

\section{TUNEL staining}

To measure DNA nicks, terminal deoxynucleotidyltransferase-mediated dUTP nick-end labeling (TUNEL) staining was performed, using ApopTag $^{\circledR}$ in situ apoptosis detection kit (Chemicon,
Temecula, CA) according to the manufacturer' $\mathrm{s}$ protocol. For negative controls, TUNEL staining was performed in the absence of TdT. For the counter-staining, the sections were stained with methyl green. To determine the percentage of apoptotic cells, micrographs of TUNEL-positive nuclei and methyl green-stained nuclei were captured using an Olympus microscope, and the cell number was counted using the ImageJ software (ImageJ version $1.43 \mathrm{r}$; NIH) from 20 random fields at $400 \mathrm{x}$ magnification.

\section{Assessment of Bcl-2, Bax, and caspase-3}

To assess the presence of Bcl-2, Bax, and cleaved (activated) caspase-3, immunohistochemical techniques were utilized, as described previously ${ }^{14)}$, with rabbit polyclonal anti-Bcl-2, anti-Bax (Santa Cruz Biotechnology Inc., Santa Cruz, CA), anti-(cleaved caspase-3) primary antibody (Cell Signaling, Beverly, MA) and Vectastain Elite $\mathrm{ABC}$ kit (Vector Laboratories, Burlington, $\mathrm{ON}$ ). After color development with 3,3'-diaminobenzidine tetrahydrochloride (DAB), the sections were evaluated at $200 x$ or $400 x$ magnification. The color intensity of $\mathrm{DAB}$ staining was measured using Image $\mathrm{J}$ software. For the quantitative comparison in the assessment of activated caspase-3, the value for the sham group was arbitrarily set 1.0 .

\section{Statistical analysis}

Values were expressed as means \pm SEM. Statistical analysis for a single comparison was performed by Student' s t-test. When necessary, multiple comparisons were performed using one-way ANOVA, followed by the Tukey post hoc test using SPSS software (IBM SPSS Statistics; version 19, Armonk, NY, USA). The statistical significance was considered to be $P<0.05$.

\section{Results}

\section{Determination of the optimal period of} ischemia with ketamine/xylazine anesthetization

As the extent of renal injury is correlated with periods of ischemia ${ }^{16,17)}$, the efficacy of the extract in protecting the kidney against ischemia/reperfusion injury might also depend on the periods of ischemia. Thus, we tested the efficacy, using serum creatinine levels as an indicator for the renal function, at varying periods of ischemia: $30,35,40$ or $45 \mathrm{~min}$ 
(Fig. 1). In a rat model of $\mathrm{I} / \mathrm{R}$, rats underwent removal of the right kidney and subsequent occlusion of the remaining left kidney by clamping for 30, 35, 40 or $45 \mathrm{~min}$ to induce ischemia, followed by $24 \mathrm{hr}$ of reperfusion. Four hundred $\mathrm{mg} / \mathrm{kg}$ of the extract, the dose of which were found to be effective in our previous studies ${ }^{9,10)}$, was administered by intraperitoneal injection $1 \mathrm{hr}$ prior to occlusion of the remaining left kidney. Serum creatinine levels in the vehicle-treated group increased sharply from 30 to $35 \mathrm{~min}$ of ischemia, and then increased gradually (Fig. 1A). Serum creatinine levels in the extract-treated group also displayed similar trend as those in the vehicle-treated group with lower values at the same periods of ischemia. When serum creatinine levels in the extract-treated group and vehicle-treated group were compared each other, serum creatinine levels in the extract-treated group were significantly reduced compared with those in the vehicle-treated group at the $40 \mathrm{~min}$ of ischemia $(2.6 \pm 0.4$ versus $4.2 \pm 0.2$ $\mathrm{mg} / \mathrm{dL}, \quad P<0.05)$. Thus, $40 \mathrm{~min}$ of ischemia was chosen as the best condition for the following experiments

\section{Ameliorating effect of enflurane against}

\section{renal injury}

As isoflurane, a volatile anesthetic, has been reported to display renal protection activity against ischemia/reperfusion injury, compared with ketamine/xylazine ${ }^{18)}$, we examined whether enflurane, another volatile anesthetic, also conferred the same activity, either alone or in combination with the extract, for which serum creatinine levels between in enflurane-anesthetized group and in ketamine/xylazine-anesthetized group at $40 \mathrm{~min}$ of ischemia were compared (Fig. 1B). For the vehicle-treated and extract-treated groups, serum creatinine levels in the enflurane-anesthetized group tended to be reduced, albeit statistically insignificantly $(2.7 \pm 0.7$ versus $4.2 \pm 0.2 \mathrm{mg} / \mathrm{dL}$ and $1.1 \pm 0.3$ versus $2.6 \pm 0.4 \mathrm{mg} / \mathrm{dL}$, respectively, $P>0.05)$, compared with those in ketamine/xylazine-anesthetized group. However, when compared between the extract-treated group and the vehicle-treated group in the respective anesthetic group, there was larger reduction of serum creatinine levels in the enflurane-anesthetized group $(1.1 \pm 0.3$ versus $2.7 \pm 0.7 \mathrm{mg} / \mathrm{dL}, P<0.05)$ compared with those in the ketamine/xylazine-anesthetized group $(2.6 \pm 0.4$ versus $4.2 \pm 0.2 \mathrm{mg} / \mathrm{dL}, P<0.05)$.

The results indicate that enflurane anesthetization is better than ketamine/xylazine anesthetization in augmenting efficacy of the extract in protecting kidney. Taken together, the combination of experimental conditions exhibiting the maximal efficacy (enflurane anesthetization with $40 \mathrm{~min}$ of ischemia) was chosen for the further experiments.

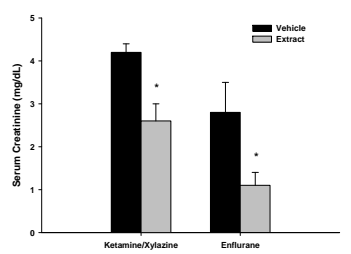

(A)

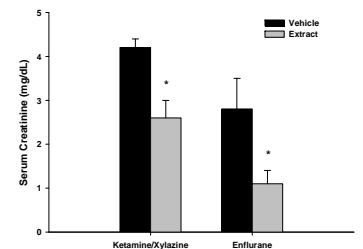

(B)
Fig. 1. Determination of the optimal ischemic time with ketamine/xylazine anesthetization and ameliorating effect of enflurane.

A. Serum creatinine levels in the vehicle-treated (I/R) and extract-treated $(\mathrm{I} / \mathrm{R}+400 \mathrm{mg} / \mathrm{kg}$ extract) group were measured after renal $\mathrm{I} / \mathrm{R}$ injury under ketamine/xylazine anesthetization. I/R injury was generated by 30 , 35,40 and $45 \mathrm{~min}$ clamping of the left renal artery in Sprauge-Dawley rats after surgical removal of the right kidney, followed by $24 \mathrm{hr}$ restoration of blood circulation. In the extract-treated group, rats received the extract $(400 \mathrm{mg} / \mathrm{kg})$ dissolved in $0.9 \%$ saline by intraperitoneal injection $1 \mathrm{hr}$ prior to occlusion. In the vehicle-treated group, rats received $0.9 \%$ saline only by intraperitoneal injection $1 \mathrm{hr}$ prior to occlusion. The numbers of rats (n) used in the vehicle-treated, and extract-treated group were 4,4 at $30 \mathrm{~min} ; 5,5$ at $35 \mathrm{~min} ; 14,15$ at $40 \mathrm{~min}$ and 5,5 at $45 \mathrm{~min}$ of ischemia, respectively. Each column represents the means $\pm \mathrm{S} . \mathrm{E} . * P<0.05$ vs. control group.

B. Serum creatinine levels in the vehicle-treated and extract-treated group were measured after renal ischemia/reperfusion injury under ketamine/xylazine anesthetization and enflurane anesthetization. Experimental conditions were the same as in Fig. 1A, except that rats were anesthetized also with enflurane, as well as with ketamine/xylazine, and ischemic time was fixed at $40 \mathrm{~min}$. For the direct comparison, data for ketamine/xylazine anesthetization was taken from Fig. 1A. The numbers of enflurane-anethetized rats used in the vehicle-treated, and extract-treated group were 5 and 5 , respectively. Each column represents the means \pm S.E. ${ }^{*} P<0.05$ vs. control group.

\section{Effect of reperfusion period on renal}

\section{function and tubular damage}

To assess the effect of reperfusion periods on the renal function, serum creatinine levels were measured at 3, 6, 12, 18, 24 or $48 \mathrm{hr}$ of reperfusion (Fig. 2A). Serum creatinine levels in vehicle-treated group reached peak at $18 \mathrm{hr}$ of reperfusion and decreased continuously afterwards (Fig. 2A). Serum creatinine levels in the extract-treated group also displayed similar trend with much lower values at the corresponding periods of reperfusion, compared with those in the vehicle-treated group. When serum creatinine levels were compared between the extract-treated group and the vehicle-treated group, serum creatinine levels in the extract-treated group were significantly reduced compared with those in the vehicle-treated group at $12 \mathrm{hr} \quad(1.6 \pm 0.2$ versus $2.3 \pm 0.1 \mathrm{mg} / \mathrm{dL}, P<0.05), 18 \mathrm{hr}(1.8 \pm 0.4$ versus $3.3 \pm 0.1 \mathrm{mg} / \mathrm{dL}, P<0.01)$ and $24 \mathrm{hr}$ of reperfusion 
$(1.3 \pm 0.2$ versus $2.7 \pm 0.3 \mathrm{mg} / \mathrm{dL}, P<0.01)$ (Fig. $2 \mathrm{~A})$, with maximal efficacy occurring at 18 and $24 \mathrm{hr}$ of reperfusion. To examine whether reduction of serum creatinine levels might be associated with protection of tubular cells in outer medulla regions against I/R injury, sections stained with H\&E were assessed (Fig. 2B). Representative micrographs at $24 \mathrm{hr}$ of reperfusion revealed that the tubules in the vehicle-treated group underwent damage represented by distinctive morphological changes of the tubules, loss of nuclei and concomitant death of tubular epithelial cells, and desquamation of viable and necrotic cells, compared with those in the sham group (Fig. 2B). The extent and severity, to some extent, of injury of the tubules in the extract-treated group were markedly reduced, compared with those in the vehicle-treated group (Fig. 2B). To quantify the extent of injury at various periods of reperfusion, grading system with 5-point scale (0-4) was adopted as described in Materials and Method section (Fig. 2C). Consistent with the qualitative findings, tubular damage in the extract-treated group were significantly attenuated, compared with that in the vehicle-treated group at $18 \mathrm{hr}$ (average score $1.8 \pm 0.3$ versus $3.4 \pm 0.2, P<0.05$ ) and $24 \mathrm{hr}$ of reperfusion (average score $1.8 \pm 0.1$ versus $3.5 \pm 0.3, P<0.01$ ), where "score 0" represents no damage as was confirmed in the sham group. Thus, temporal alterations of efficacy of the extract assessed by renal function were strongly correlated with those assessed by cellular injury.

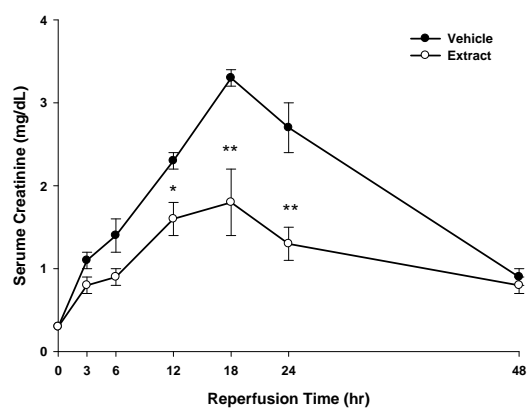

(A)

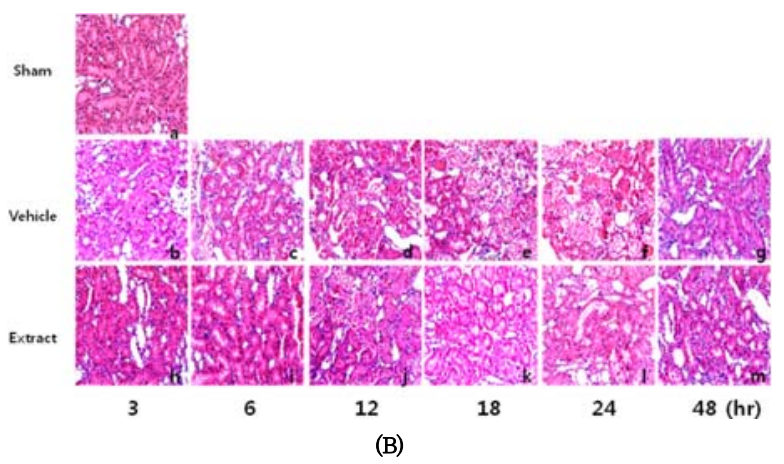

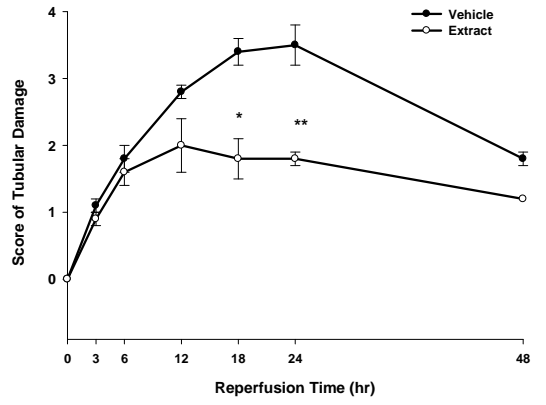

(C)

Fig. 2. Effect of reperfusion period on renal function and tubular damage.

A. Serum creatinine levels in the vehicle-treated and extract-treated group were measured after renal ischemia/reperfusion injury under enflurane anesthetization. Experimental conditions were the same as in Fig. $1 \mathrm{~B}$, except that reperfusion times were $3,6,12,18,24$ and $48 \mathrm{hr}$. Reperfusion time " 0 " at the $x$-axis represents sham experiments, with the number of rats used being $4(n=4)$. The numbers of rats used in the vehicle-treated, and extract-treated group at the corresponding reperfusion time points were as follows: $4 \quad(n=4)$ (vehicle-treated), 4 $(\mathrm{n}=4)($ extract-treated) at $3 \mathrm{hr} ; 4,4 \mathrm{at} 6 \mathrm{hr} ; 8,8$ at $12 \mathrm{hr} ; 8,8$ at 18 $\mathrm{hr} ; 11,11$ at $24 \mathrm{hr} ; 4,5$ at $48 \mathrm{hr}$ of reperfusion, respectively. The serum creatinine levels at each time point represent the means \pm S.E. $* * P<0.01$ and $* P<0.05$ vs. control group.

B. Representative photomicrographs of renal tissue sections harvested from rats presented in Fig. 2A and stained with haematoxylin \& eosin (H\&E) at magnification $200 \times$ were illustrated: (a) sham $(\mathrm{n}=4)$; (b) and (h), 3 hr; (c) and (i), $6 \mathrm{hr}$; (d) and (j), $12 \mathrm{hr}$; (e) and (k), $18 \mathrm{hr}$; (f) and (l), $24 \mathrm{hr}$; $(\mathrm{g})$ and $(\mathrm{m}), 48 \mathrm{hr}$ of reperfusion, respectively. The number of rats was the same as in Fig. $2 \mathrm{~A}$

C. Semi-quantitative assessment with H\&E of the histological alterations due to tubular damage was presented with 5-point scale system: 0 , none (no change); 1, <5\% (mild); 2, 5-30\% (moderate); 3, 30-50\% (severe); $4,>50 \%$ (very severe). The scores at each time point represent the means \pm S.E. ${ }^{* *} P<0.01$ and ${ }^{*} P<0.05$ vs. vehicle group.

\section{Involvement of apoptosis in the}

\section{attenuation of tubule damage by extract}

Levels of DNA nicks and cleaved caspase-3 measured by TUNEL staining and immunohistochemistry, respectively, were selected as indices to assess the extent of apoptosis that occurred in the tubular epithelial cells at varying periods of reperfusion (Fig. 3A, B, C and D). Representative micrographs stained with TUNEL revealed apoptotic cells in the tubules of the sham, vehicle-treated and extract-treated group (Fig. 3A). The number of apoptotic cells in the vehicle-treated group increased continuously up to $24 \mathrm{hr}$ of reperfusion, then decreased sharply at $48 \mathrm{hr}$ of reperfusion, although that in the vehicle group was still larger than that in the sham group even at $48 \mathrm{hr}$ of reperfusion. The number of apoptotic cells in the extract-treated group also displayed similar trend as those in the vehicle-treated group with lower number of apoptotic cells at the corresponding periods of reperfusion. To quantify the findings, the ratio of apoptotic cells to total cells, [Apoptotic cell (\% total cell)], was assessed (Fig. 3B). The ratio was the most significantly reduced in the extract-treated group 
compared with that in the vehicle-treated group $(13.7 \pm 6.7$ versus $36 \pm 8.4 \%, P<0.05)$ at $24 \mathrm{hr}$ of reperfusion. As another hallmark for assessing apoptosis, the relative amount of cleaved caspase-3 (activated caspase-3) was also examined at $24 \mathrm{hr}$ of reperfusion (Fig. 3C, D). Representative micrographs stained with an antibody that specifically binds to cleaved caspase-3 (activated caspase-3) also revealed apoptotic cells in the tubules of the sham, vehicle-treated and extract-treated group (Fig. 3C, D). Consistent with the findings observed with TUNEL staining, color intensity in the vehicle-treated group that reflects the number of apoptotic cells increased markedly, compared with that in the sham group, whereas the color intensity in the extract-treated group was attenuated, compared with that in the vehicle-treated group (Fig. 3C). To quantify these findings, color intensity in each group was compared (Fig. 3D). The color intensity was significantly reduced in the extract-treated group compared with that in the vehicle-treated group $(5.2 \pm 0.2$ versus $10.2 \pm 0.1$ $\%, P<0.05)$, when the color intensity in the sham group was arbitrarily set 1.0 . With apoptotic cascades considered, the results suggest that generation of nicks on DNA was mediated by activation of procaspase -3 to caspase -3 , an execution caspase.
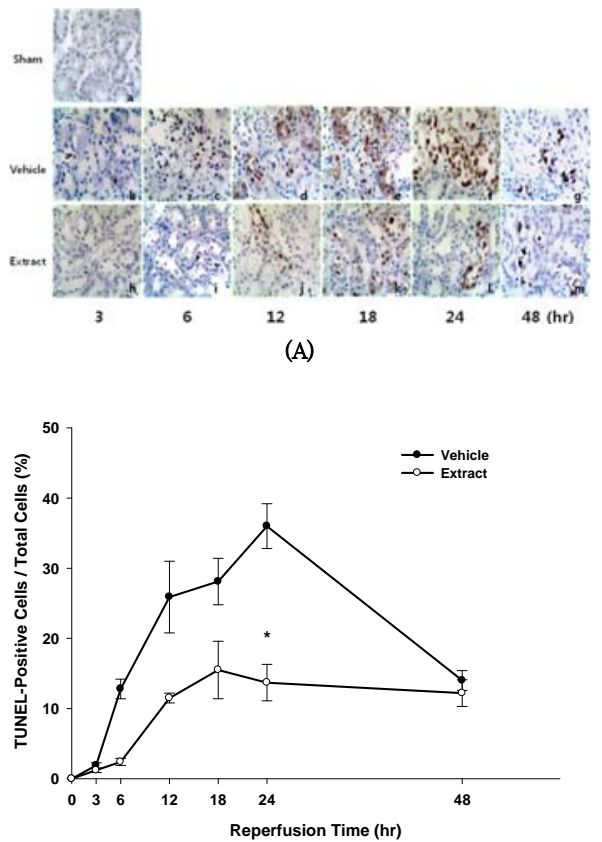

(B)

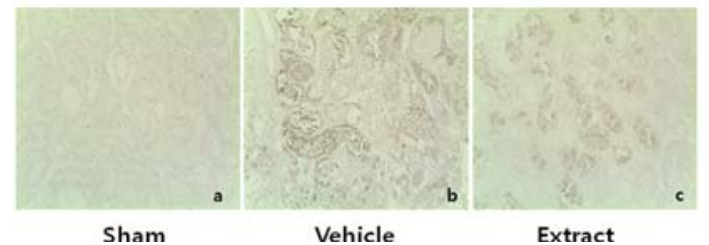

(C)

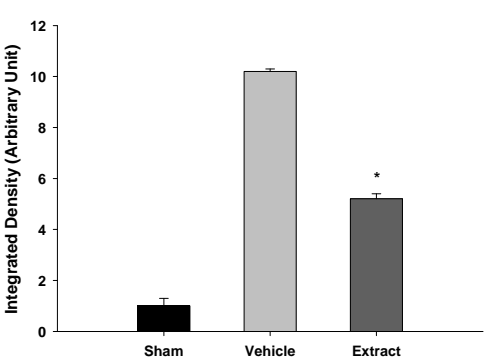

(D)

Fig. 3. Involvement of apoptosis in the attenuation of tubule damage by extract.

A. Representative photomicrographs of renal tissue sections harvested from rats presented in Fig. 2A and stained with TUNEL at magnification $200 \times$ were illustrated: (a) sham $(\mathrm{n}=4)$; (b) and (h), $3 \mathrm{hr}$; (c) and (i), 6 hr; (d) and (j), $12 \mathrm{hr}$; (e) and (k), $18 \mathrm{hr}$; (f) and (l), $24 \mathrm{hr}$; (g) and $(\mathrm{m}), 48 \mathrm{hr}$ of reperfusion, respectively. The number of rats was the same as in Fig. 2A.

B. Quantitative assessment of TUNEL-positive cells was presented with the ratio of TUNEL-positive cells/total cells. The ratios at each time point represent the means \pm S.E. ${ }^{*} P<0.05$ vs. control group.

C. Representative photomicrographs of renal tissue sections harvested from rats at $24 \mathrm{hr}$ of reperfusion presented in Fig. 2A and stained with immunohistochemistry for activated caspase-3 at magnification $400 \mathrm{x}$ were presented: (a) sham $(n=3)$, (b) vehicle-treated $(n=6)$, and (c) extract-treated group $(n=6)$, respectively.

D. Quantitative assessment of activated caspase-3 produced from cleavage of procaspase-3 was presented, with the value for the sham group arbitrarily set 1.0 . Each column represents the means \pm S.E. ${ }^{*} P\langle 0.05$ vs. vehicle-treated group.

\section{Association of Bcl-2 and Bax in}

\section{mediating antiapoptotic effect of extract}

Expression levels of Bcl-2 and Bax at $24 \mathrm{hr}$ of reperfusion were evaluated by immunohistochemistry to obtain $\mathrm{Bax} / \mathrm{Bcl}-2$ ratio that serves as the key determinant $^{19)}$ (Fig. 4A and 4B). Representative micrographs revealed that color intensity of Bcl-2 and Bax in the vehicle-treated group decreased and increased markedly, respectively, compared with that in the sham group, whereas color intensity of Bcl-2 and Bax in the extract-treated group increased and decreased, respectively, compared with that in the vehicle-treated group (Fig. 4A). To quantify these findings, Bax/Bcl-2 ratios were assessed (Fig. 4B). The ratio was significantly reduced in the extract-treated group compared with that in the vehicle-treated group $(1.4 \pm 0.2$ versus $2.5 \pm 0.3, P<0.05)$, whereas that in the sham group remained relatively low $(1.0 \pm 0.3)$.

\section{Reduction of MDA levels by the extract}

To correlate reduction of apoptosis with inhibition of ROS production, MDA levels in the tissue, a hallmark of lipid peroxidation, were chosen as an indicator representing ROS because MDA levels are positively correlated with generation of $\mathrm{ROS}^{11)}$. MDA levels in the kidney tissue were significantly reduced in the extract-treated group compared with those in 
the vehicle-treated group $(122.6 \pm 16.8$ versus $166.4 \pm 6.2$ $\%, P<0.05)$, when MDA levels in the sham group were arbitrarily set $100 \%$ (Fig. 4C). The results suggest that the extract inhibited the production of $\mathrm{MDA}$, presumably mediated by blocking the generation of ROS.

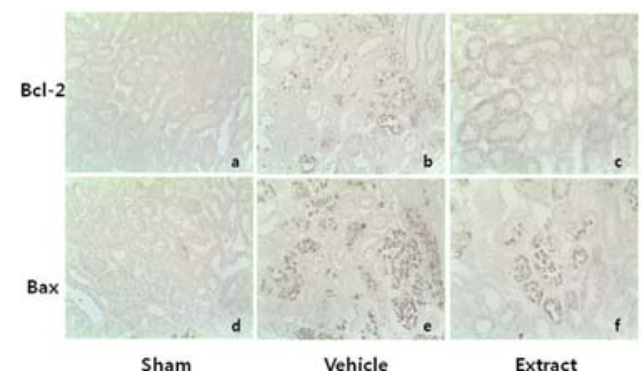

(A)

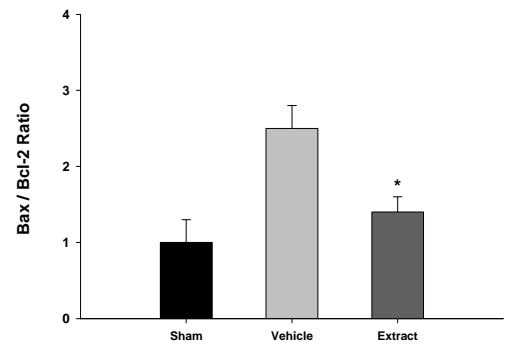

(B)

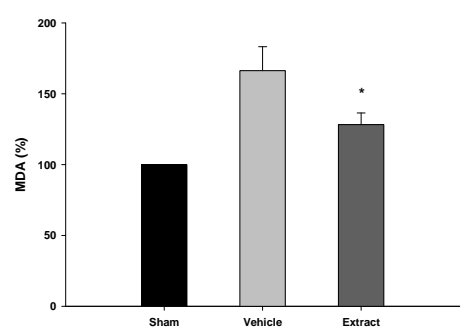

(C)

Fig. 4. Association of $\mathrm{Bcl}-2$ and Bax in mediating antiapoptotic effect of extract and reduction of MDA levels.

A. Representative photomicrographs of renal tissue sections harvested from rats at $24 \mathrm{hr}$ of reperfusion presented in Fig. 2A and stained with immunohistochemistry for Bcl-2 and Bax at magnification 400x were presented: (a), (b), and (c); $\mathrm{Bcl}-2$ for sham ( $\mathrm{n}=3)$, vehicle-treated $(n=6)$, and extract-treated group $(n=6)$, respectively, (d), (e), and (f); Bax for sham $(n=3)$, vehicle-treated $(n=6)$, and extract-treated group $(n=6)$, respectively.

B. Quantitative assessment of $\mathrm{Bax} / \mathrm{Bcl}-2$ ratio was presented, with the value for the sham group arbitrarily set 1.0. Each column represents the means \pm S.E. ${ }^{*} P<0.05$ vs. vehicle-treatedgroup.

C. Renal tissue MDA levels in the sham $(n=3)$, vehicle-treated $(n=7)$ and extract-treated group $(n=7)$ were measured from rats at $24 \mathrm{hr}$ of reperfusion, where the value for the sham group arbitrarily set $100 \%$. Each column represents the means \pm S.E. $* P<0.05$ vs. vehicle-treated group.

\section{Discussion}

In the present study, we demonstrated that administration of the extract by intraperitoneal injection prior to ischemia protected the rat kidney against $\mathrm{I} / \mathrm{R}$ injury mediated by reduction of MDA generation and consequent inhibition of apoptotic cascades. Obstruction of the renal artery by clamping in a rat leads the kidney to anoxic state, and consequent depletion of ATP triggers cascades of events in the cells, which eventually result in the cell death by apoptosis or necrosis, depending on the severity and duration of ATP depletion ${ }^{7,16,20)}$. Renal injury becomes exacerbated with increasing duration of ischemia $^{16)}$. In this study, we also observed that serum creatinine levels, a hallmark of renal function, rose with increasing duration of ischemia (30 - 45 min). However, the maximal efficacy of the extract occurred at $40 \mathrm{~min}$ of ischemia, reflecting a compromise between the extent of renal injury and the capability of the extract in protecting the kidney; at the shorter period of ischemia (30 min), renal injury itself might be too mild for the efficacy to be observed. On the other hand, at the longer period of ischemia (45 min), renal injury might be too severe so that renoprotecting capability of the extract cannot reverse its demise.

We also observed that efficacy of the extract was better in rats anesthethized with enflurane, another inhalant anesthetic, than with ketamine/xylazine. Inhalant anesthetics have a unique property among anesthetics; Kim et al. ${ }^{18)}$ reported that isoflurane, a volatile anesthetic, protected against renal I/R injury compared with other anesthetics, such as ketamine/xylazine and pentobarbital sodium. The protection is mediated by activation of sphingosine kinase and subsequent synthesis of sphingosine-1-phosphate by the kinase ${ }^{21)}$. Thus, augmentation of the efficacy in enflurane-anesthetized rats might represent cumulative effects of the extract and enflurane. Although prompt reperfusion is of critical importance in order to limit renal injury resulting from ischemia, paradoxically, however, reperfusion itself exerts more injury to the ischemic, weakened cells due to accelerated generation of $\mathrm{ROS}^{5,6}$. As a result, serum creatinine levels reach a peak before they are reversed to normal when ischemia is followed by reperfusion ${ }^{22)}$. Under our experimental conditions (enflurane anesthetization, $36{ }^{\circ} \mathrm{C}$ body temperature, and $40 \mathrm{~min}$ of ischemia), serum creatinine levels reached the peak at $18 \mathrm{hr}$ of reperfusion, around the time points of which the maximal efficacy of the extract was also observed, when assessed by degree of the reduction of serum creatinine levels. When the temporal pattern for renal tissue injury was compared with that for serum creatinine levels, a similar trend was revealed, with the maximal efficacy occurring at $24 \mathrm{hr}$ of reperfusion. A sudden burst of ROS production in the renal tissue following reperfusion plays an important role in the progression of renal tissue injury; for example, ROS generated intracellularly results in lipid 
peroxidation on polyunsaturated fatty acids, a constituent of cellular membranes, yielding lipid peroxides, of which malondialdehyde (MDA) is the most abundant ${ }^{23)}$. Thus, tissue MDA levels are positively correlated with tissue ROS levels. Products like MDA mediates a cascade of events, leading to increase of $\mathrm{Bax} / \mathrm{Bcl}-2$ ratio, increase of which subsequently amplifies signals responsible for apoptotic cell death $^{23,24)}$. One such crucial signal is cleavage of procaspase -3 to active caspase -3 , an execution caspase, and caspase-3 mediates generation of nicks on DNA, the amount of which can be assessed by TUNEL ${ }^{19,24,25)}$ In the present study, pretreatment with the extract attenuated tissue MDA levels in the $\mathrm{I} / \mathrm{R}$ rat model, suggesting that the extract acts as a ROS scavenger. Consistent with the present study, we have shown that the extract also inhibited generation of ROS in the cultured neuronal cells via up-regulation of glutathione, a hallmark of endogenous antioxidant levels ${ }^{9)}$. Consequently, inhibition of ROS production by the extract results in blocking a cascade of events involved in apoptosis: decrease of $\mathrm{Bax} / \mathrm{Bcl}-2$ ratio, blockade of caspase-3 activation, and reduction of generation of nicks on DNA. The final consequence of these events leads to improvement of cell survival from I/R injury, which might also prevent downstream inflammation. In connection with this, we have already demonstrated that administration of the extract attenuated brain injury by inhibiting inflammatory reactions in rats subjected to hypoperfusion for 3 weeks ${ }^{10)}$.

\section{Conclusion}

In this study, we demonstrated that administration of the extract by intraperitoneal injection was effective in protecting against renal injury in a rat model of $\mathrm{I} / \mathrm{R}$ by reducing generation of MDA acting as an antioxidant, subsequently leading to inhibiting apoptosis. Thus, the extract that can be prepared easily by boiling the ground Triticum aestivum L. might be developed as a renal protectant in a clinical setting of ischemic acute renal failure caused by shock or cardiac surgery. This study could extend clinical applications of Triticum aestivum L. to include renal diseases as well as palpitations, insomnia and lack of concentration already prescribed in traditional Chinese medicine.

\section{Acknowledgement}

This research was supported by High Value-added
Food Technology Development Program, Ministry for Food, Agriculture, Forestry and Fisheries, Republic of Korea.

\section{References}

1. Venkataraman R, Kellum JA. Defining acute renal failure: the RIFLE criteria. J Intensive Care Med. 2007 ; 22 : 187-93.

2. Abuelo JG. Normotensive ischemic acute renal failure. N Engl J Med. 2007 ; 357 : 797-805.

3. Lameire $\mathrm{N}$, Van Biesen $\mathrm{W}$, Vanholder $\mathrm{R}$. Acute renal failure. Lancet. 2005 ; 365 : 417-30.

4. Bonventre JV. Mechanisms of ischemic acute renal failure. Kidney Int. 1993 ; 43 : 1160-78.

5. Nath KA, Norby SM. Reactive oxygen species and acute renal failure. Am J Med. 2000 ; 109 : $655-78$.

6. Chatterjee PK. Novel pharmacological approaches to the treatment of renal ischemia-reperfusion injury: a comprehensive review. Naunym-Schmiedeberg' s Arch Pharmacol. 2007 ; 376 : 1-43.

7. Pandanilam BJ. Cell death induced by acute renal injury: a perspective on the contributions of apoptosis and necrosis. Am J Physiol Renal Physiol. 2003 ; 284 : F608-F27.

8. Wing YK. Herbal treatment of insomnia. Hong Kong Med J. 2001 ; 7 : 392-402.

9. Jang JH, Kim CY, Lim SH, Yang CH, Song KS, Han HS, Lee HK, Lee JW. Neuroprotective effects of Triticum aestivum L. against $\beta$ -amyloid-induced cell death and memory impairments. Phytother Res. 2010 ; 24 : 76-84.

10. Han HS, Jang JH, Choi JS, Kim YJ, Lee C, Lim $\mathrm{SH}$, Lee HK, Lee JW. Water extract of Triticum aestivum $\mathrm{L}$. and its components demonstrate protective effect in a model of vascular dementia. J Med Food. 2010 ; 13 : 572-78.

11. Guz G, Demirogullari B, Ulusu NN, Dogu C, Demirtola A, Kavutcu M, Omeroglu S, Stefek M, Karasu C. Stobadine protects rat kidney against ischaemia/reperfusion injury. Clin Exp Pharmacol Physiol. 2007 ; 34 : 210-6.

12. Jung HJ, Kim MJ, Lim SH, Park JH, Lee HK, Ahn KS, Lee JW. The effect of extract of Paeonia lactiflora on the improvement of ischemic acute renal failure. Korean $\mathrm{J}$ Nephrol. 2009 ; 28 : $180-9$.

13. Kakuta Y, Okumi M, Isaka Y, Tsutahara K, Abe T, Yazawa K, Ichimaru N, Matsumura K, Hyon SH, Takahara S, Nonomura N. Epigallocatechin-3-gallate protects kidneys from ischemia reperfusion injury 
by $\mathrm{HO}-1$ upregulation and inhibition of macrophage infiltration. Transpl Int. 2011 ; 24 : 514-22.

14. Lim SH, Song KS, Lee JW. Butyrate and propionate, short chain fatty acids, attenuate myocardial damages by inhibition of apoptosis in a rat model of ischemia-reperfusion. J Korean Soc Appl Biol Chem. $2010 ; 53: 570-7$.

15. Kelly KJ, Williams, Jr WW, Colvin RB, Meehan SM, Springer TA, Gutierrez-Ramos JC, Bonventre $\mathrm{JV}$. Intracellular adhesion molecule-1-deficient mice are protected against ischemic renal injury. $\mathrm{J}$ Clin Invest. 1996 ; 97 : 1056-63.

16. Jablonski P, Howden BO, Rae DA, Birrell CS, Marshall VC, Tange J. An experimental model for assessment of renal recovery from warm ischemia. Transplantation. 1983 ; 35 : 198-204.

17. Raman RN, Pivetti CD, Ramsamooj R, Matthews DL, Demos SG, Troppmann C. Factors influencing rat survival in a warm renal ischemia model: time to adapt the protocols. Transplant Proc. 2011 ; 43 : 1511-4

18. Kim MJ, Kim MH, Kim NL, VD D' Agati, CW Emala, Sr, HT Lee. Isoflurane mediates protection from renal ischemia-reperfusion injury via sphingosine kinase and sphingosine-1-phosphate-dependent pathways. Am J Physiol Renal Physiol. 2007 ; 293 : F1827-F35.

19. Korsmeyer SJ. BCL-2 gene family and the regulation of programmed cell death. Cancer Res. 1999 ; 59 : 1693s-799s.

20. Heyman SN, Rosenberger C, Rosen S. Experimental ischemia-reperfusion: biases and myths-the proximal vs. distal hypoxic tubular injury debate revisited. Kidney Int. 2010 ; 77 : 9-16.

21. Kim MH, Kim MJ, Park SW, Pitson SM, Lee HT. Isoflurane protects human kidney proximal tubule cells against necrosis via sphingosine kinase and sphingosine-1-phosphate generation. Am J Nephrol. $2010 ; 31: 353-62$.

22. Saenz-Morales D, Conde E, Blanco-Sanchez I, Ponte B, Aguado-Fraile E, de las Casas G, Garcia-Martos M, Alegre L, Escrbese MM, Molina A, Santiuste C, Liano F, Garcia-Bermejo G. Differential resolution of inflammation and recovery after renal ischemia-reperfusion injury in Brown Norway compared with Sprague Dawley rats. Kidney Int. $2010 ; 77$ : 781-93.

23. Gueraud F, Atalay M, Bresgen N, Cipak A, Eckl PM, Huc L, Jouanin I, Siems W, Uchida K. Chemistry and biochemistry of lipid peroxidation products. Free Radic Res. 2010 ; 44 : 1098-124.

24. Havasi A, Borkan SC. Apoptosis and acute kidney injury. Kidney Int. $2011 ; 80$ : 29-40.
25. Wagner M, Cadetg P, Ruf R, Mazzuchelli L, Ferrari P, Redaelli CA. Heme oxygenase-1 attenuates ischemia/reperfusion-induced apoptosis and improves survival in rat renal allografts. Kidney Int. $2003 ; 63: 1564-73$. 